\title{
Congenital malaria: an overview
}

\author{
CHIGOZIE J. UNEKE \\ Department of Medical Microbiology/Parasitology, Faculty of Clinical Medicine, Ebonyi State University, PMB \\ 053 Abakaliki, Nigeria \\ E-mail: unekecj@yahoo.com
}

\begin{abstract}
Congenital malaria is a public health concern globally. This report reviews publications on congenital malaria in the last two decades (1990-2010) with the view to establishing the current global epidemiological trends and the public health implications. A Medline Entrez-PubMed search was performed and published studies on congenital malaria in the last two decades (1990-2010) were identified. A combination of key words "congenital malaria" were used for the search which yielded 180 publications as of December 2010. Of the 180 publications, 93 were within the period 1990 to 2010. Bibliographies of all publications selected were checked for additional relevant references and were obtained and included in the review. The critical issues identified and discussed include the (i) current global trends of congenital malaria; (ii) controversies associated with the frequency of occurrence of congenital malaria; (iii) mechanism and clinical features; (iv) role of maternal HIV infection (v) effects of congenital malaria on infants; (vi) diagnostic challenges; and (vii) treatment considerations. Operational research into various aspects of congenital malaria is essentially lacking as many unresolved issues requiring urgent scientific investigation abound. Public health policy on malaria control should integrate guidelines on congenital malaria management and control.
\end{abstract}

Keywords: Plasmodium; malaria, congenital; diagnosis, treatment, pregnancy

\section{Introduction}

Malaria continues to remain the most severe and complex health challenge facing the vast majority of the countries in tropical and sub-tropical regions of the world. It is one of the most predominant infectious diseases associated with underdevelopment, poverty and ignorance (Worral et al., 2005). Malaria is still a major contributor to high rate of the global infectious disease-related mortality and morbidity particularly in Africa, South-East Asia, Eastern Mediterranean Regions and parts of South America (WHO 2008). In the World Malaria Report (WMR) of 2009 the World Health Organization (WHO) estimated that 243 million cases of malaria occurred worldwide in 2008, and majority of the cases (85\%) occurred in the African Region, followed by the South-East Asia (10\%) and Eastern Mediterranean Regions (4\%) (WHO 2009). According to the WMR, malaria accounted for an estimated 863,000 deaths in 2008, of which $89 \%$ were in the African Region, followed by the Eastern Mediterranean $(6 \%)$ and the South-East Asia Regions (5\%) (WHO, 2009).

Plasmodium falciparum is considered as more dangerous than the other three species $(P$. vivax, $P$. malariae and $P$. ovale) of the human malaria parasites because it is responsible for virtually all the severe malaria cases and deaths (WHO, 1997; 2000a). The sub-Saharan Africa remains the region with the highest burden of malaria accounting for nearly $90 \%$ of global malaria deaths because $P$. falciparum is the predominant species and the most effective malaria vector - the mosquito Anopheles gambiae - is the most widespread in the region and the most 
difficult to control (WHO, 1992). However, increasing number of reports has indicated that $P$. vivax is also associated with significant malaria disease especially in parts of Asia and South America (Nimir et al., 2006; Guerra et al., 2010).

In areas of high malaria endemicity most of the malaria-associated morbidity and mortality are recorded in young children (Uneke, 2009a; Snow et al., 2004). Available evidence indicates that pregnant women are also highly vulnerable to malaria in these endemic areas (Uneke, 2007a; Tagbor et al., 2008; Schantz-Dunn \& Nour, 2009; Davis et al., 2010). However, the impact of the malaria burden is much more devastating among children particularly in subSaharan African region. Almost all of the malaria deaths in sub-Saharan Africa occur in children below five years of age and this translates to the child mortality of nearly 1 million each year (DFID, 2004; Hopkins et al., 2007; WHO, 2008). Indeed, a child dies of malaria every 30 seconds, a death toll of about 3000 children every day in the sub region alone (WHO, 2003, 2008). Reports from studies and reviews within the last few years are of the consensus that malaria causes at least $20 \%$ of all deaths in children under 5 years of age in sub-Saharan Africa (Rowe et al., 2006; Gyapong \& Garshong, 2007; Hopkins et al., 2007; Sharp et al., 2007). However, it is pertinent to state that many of the reports presenting data on the burden of malaria among young children appear not to focus on infant specifically (Larru et al., 2009). This is presumably because it is thought that infants under the age of six months are relatively protected against clinical malaria as a result of maternal antibodies transfer and the presence of foetal haemoglobin (Snow et al., 1998; Klein Klouwenberg et al., 2005; Duah et al., 2010). However, findings from a number of hospital-and community-based studies within sub-Saharan Africa suggest that the burden of malaria during the six first months of life may be substantial (Afolabi et al., 2001; Nweneka \& Eneh 2004; Larru et al., 2009). Thus the burden of malaria among young children might be higher than what is generally estimated.

The high burden of childhood malaria in endemic regions of the world has been associated with malaria during pregnancy (Murphy \& Breman 2001). In sub-Saharan Africa for instance, malaria affects an estimated 24 million pregnant women (Steketee et al., 2001) and each year between 75,000 and 200,000 infant deaths are attributed to malaria infection in pregnancy globally (Steketee et al., 2001; WHO, 2003). Pregnant women residing in malaria endemic areas often experience a high frequency and density of parasitemia, resulting to high rates of maternal morbidity including fever and severe anaemia, with abortion and stillbirth, and with high rates of placental parasitisation (Brabin 1983; Steketee et al., 2001). Severe parasitization of the placenta by malaria parasites particularly $P$. falciparum and $P$. vivax which is known as placental malaria can result in transplacental transmission of the parasite to the foetus and consequently to congenital malaria (Brabin, 1983; Menendez \& Mayor 2007; Uneke, 2007b).

Congenital malaria resulting from the transplacental transmission of malaria parasites particularly P. falciparum from mother to foetus, is well described by some early reports (Schwetz \& Peel 1934; Covell, 1950; Reinhrdt et al., 1978). However the precise definition of congenital malaria is still a subject that is not devoid of controversy debatable, but symptoms usually occur 10 to 30 days postpartum (Behrman et al., 2004). The disease can be observed in a day-old baby or be delayed for weeks or months (Hashemzadeh \& Heydarian, 2005). In 80\% of the cases of congenital malaria, the most common clinical features include fever, anaemia, and 
splenomegaly (Remington \& Klein, 1995). Some reports indicate that other signs and symptoms which could manifest are hepatomegaly, jaundice, regurgitation, loose stools, and poor feeding, and occasionally, drowsiness, restlessness, and cyanosis (Remington \& Klein 1995; Hashemzadeh \& Heydarian 2005).

In recent times there has been renewed public health concern about the increase in the burden of congenitally acquired infectious diseases including malaria (McGovern et al., 2007). The global drive towards making motherhood safer, improving perinatal outcome and enhancing neonatal health has made congenital malaria an important public health issue (Halin, 2002; van Geertruyden et al., 2004; Bhutta et al., 2005). The purpose of this paper was to review some current epidemiological developments in congenital malaria and to highlight the public health implications with respect to the management of congenital malaria, public health policy guidelines and operational research needs. In this review, congenital malaria was defined as the presence of asexual stages of malaria parasites in cord blood smear at delivery or peripheral blood smear of the baby in the first 7 days of life, irrespective of clinical symptoms.

To achieve the objective of this paper, a Medline Entrez-PubMed search was performed and reported studies on congenital malaria in the last two decades (1990-2010) were identified. A combination of key words "congenital malaria" were used for the search which yielded 180 publications as of December 2010. Of the 180 publications, 93 where within the period 1990 to 2010. The 93 publications were then selected for the review. Bibliographies of all publications selected were checked for additional relevant references and were obtained and included in the review. Particular attention was paid to articles providing information on the prevalence of congenital malaria, the clinical significance, role of maternal HIV infection, diagnosis and treatment considerations, and policies on prevention and control.

\section{Congenital malaria: rare or frequent event}

For a long time the frequency of the occurrence of congenital malaria remained a subject of controversy with many reports before the 1970s describing it as an extremely rare event (Covell, 1950; Bruce-Chwatt, 1952; Logic \& McGregor, 1970). Some other reports in the 1980s however noted that the low reported incidence of congenital malaria particularly in Africa was surprising since malaria occurs more commonly in pregnancy (McGregor, 1983; Lehner \& Andrews, 1988). More recently, findings from a number of studies from sub-Saharan Africa have described congenital malaria as a rare event largely because the prevalence of malaria parasite in cord blood or neonatal blood was very low and few newborns developed clinical disease during the first few weeks of life (Lamikanra 1993; Djibo \& Cenac, 2000; Adachi et al., 2000; Sule-Odu et al., 2002). These studies had speculated that the effectiveness of the placenta to restrain the malaria parasite passage to the foetus and the remarkable capacity of the foetus to resist infection as demonstrated by Miller \& Telford (1997) was responsible for the rarity of congenital malaria. It was further argued that the resistance to congenital malaria is enhanced by physical barrier of the placenta to infected red cells, the passive transfer of maternal antibodies, and the poor environment afforded by foetal erythrocytes for plasmodial replication, due to their foetal haemoglobin composition and low free-oxygen tension (Miller \& 
Telford, 1996). Moreover, because neonates in Africa rarely present with clinical disease, congenital malaria was assumed to be of little clinical importance in areas of high malaria endemicity (Steketee et al., 1996a).

Interestingly however, evidence from most of the cross-sectional studies conducted in parts of sub-Saharan Africa on congenital malaria within the last two decades (1990-2010) clearly indicates that congenital malaria is not as uncommon as previously thought. In fact, congenital malaria prevalence in majority of the cross-sectional studies within the last five years (2005-2010) ranged from $10.8 \%$ to as high as $54.2 \%$ (Table 1). In most of these recent reports there was a strong association between placental malaria and umbilical cord parasitaemia which was suggested to be responsible for the congenital malaria (Uneke, 2007a, b, c). Until recently, it was unclear if the presence of malaria parasites in umbilical cord blood was an indication of infection acquired antenatally or a result of contamination with infected maternal blood at delivery. In a 2006 report however, Malhotra et al. (2006) demonstrated from their study in Kenya that malaria parasites identified in cord blood were acquired antenatally by transplacental transmission of infected erythrocytes and that primigravid and secundigravid women with placental malaria were at increased risk for congenital infection. This finding therefore confirmed earlier reports which had noted that the rate of transplacental transmission of malaria in endemic region was high and suggested that the placental barrier is not very effective when infected with malaria parasites (Redd et al., 1996; Brabin et al., 2004).

Table 1: Prevalence of congenital malaria as reported by various studies in malaria endemic areas of sub-Saharan Africa from 1990-2010.

\begin{tabular}{|c|c|c|c|c|}
\hline Type of study & Study location & $\begin{array}{l}\text { Prevalence of } \\
\text { congenital } \\
\text { malaria }(\%)\end{array}$ & $\begin{array}{l}\text { Year of } \\
\text { publicati } \\
\text { on }\end{array}$ & Study authors/reference \\
\hline Cross-sectional & Lagos, Nigeria & 13.6 & 2010 & Lesi et al. \\
\hline Cross-sectional & Western Kenya & 10.8 & 2009 & Perrault et al. \\
\hline Cross-sectional & Muheza, Tanzania & 19.1 & 2008 & Mwangoka et al. \\
\hline Cross-sectional & Calabar, Nigeria & 13 & 2008 & Ekanem et al. \\
\hline Cross-sectional & Sagamu, Nigeria & 10.9 & 2008 & Sotimehin et al. \\
\hline Cross-sectional & Ibadan, Nigeria & 5.1 & 2007 & Falade et al. \\
\hline Cross-sectional & Enugu, Nigeria & 32.48 & 2006 & Okafor et al 2006. \\
\hline Retrospective & Sagamu, Nigeria & 17.4 & 2006 & Runsewe-Abiodun et al. \\
\hline Cross-sectional & Lagos, Nigeria & 15.3 & 2006 & Mukhtar et al. \\
\hline Cross-sectional & Ile-Ife, Nigeria & 54.2 & 2005 & Obiajunwa et al. \\
\hline Cross-sectional & Southern Cameroon & 7.8 & 2005 & Akum et al. \\
\hline Cross-sectional & Sagamu, Nigeria & 0.7 & 2002 & Sule-Odu et al. \\
\hline Prospective survey & Niamey, Niger & 13.3 & 2000 & Djibo \& Cenac \\
\hline Cross-sectional & $\begin{array}{l}\text { Dar-es Salaam, } \\
\text { Tanzania }\end{array}$ & 0.33 & 2000 & Adachi et al. \\
\hline Cross-sectional & Ibadan, Nigeria & 15.0 & 2000 & Olowu et al. \\
\hline Cross-sectional & Ibadan, Nigeria & 2.6 & 1997 & Achidi \& Salimonu \\
\hline Cross-sectional & Jos, Nigeria & 2.82 & 1997 & Egwunyenga et al. \\
\hline Cross-sectional & Various sites in SSA & 23.0 & 1997 & Fischer \\
\hline
\end{tabular}




$\begin{array}{lllll}\text { Cross-sectional } & \text { Central, Nigeria } & 10.5 & 1996 & \text { Egwunyenga et al. } \\ \text { Cross-sectional } & \text { Southern Malawi } & 6.7 & 1996 & \text { Redd et al. } \\ \text { Case series } & \text { Benin, Nigeria } & 8.0 & 1995 & \text { Ibhanesebhor } \\ \text { Case series } & \text { Ibadan, Nigeria } & 23.7 & 1993 & \text { Akindele et al. } \\ \text { Cross-sectional } & \text { Lagos, Nigeria } & 0 & 1993 & \text { Lamikanra } \\ \text { Cross-sectional } & \text { Maputo, Mozambique } & 1.5 & 1993 & \text { Bergstrom et al. } \\ \text { Cross-sectional } & \text { Southern Zambia } & 36.0 & 1991 & \text { Larkin \&Thuma } \\ \text { Cross-sectional } & \text { Kinsasha, DRC } & 4.0 & 1990 & \text { Omanga \&Kapepela }\end{array}$

$\mathrm{SSA}=$ sub Saharan Africa; DRC= Democratic Republic of Congo

It is thus not very unlikely that early reports which indicated that congenital malaria was a rare event in endemic areas may have underestimated the prevalence of the disease since transplacental transmission of malaria parasites was not an uncommon event even in semiimmune women who usually have high levels of anti-malaria acquired immunity (Menendez \& Mayor, 2007). It is pertinent to add that there exist a number of factors which to a large extent influence the estimation of congenital malaria. Menendez and Mayor (2007) described these factors as (i) differences in the definition of congenital malaria; (ii) levels of maternal immunity; (iii) the type of blood sample examined (peripheral blood of neonates or cord blood); (iv) the expertise in blood-smear examinations; (v) the method of parasite detection (Giemsa staining or polymerase chain reaction (PCR); or even (vi) a reflection of true environmental differences. The lack of consideration of these factors could give rise to congenital malaria underestimation. For instance Perrault et al. (2009) found 0\% of cord blood infection by microscopy and $10.8 \%$ of cord blood infection by PCR in the same population. These differences are the major limitations in the comparison of studies on congenital malaria and so the interpretation should be done cautiously. Despite finding that $13.3 \%$ of neonates examined had malaria parasite Djibo \& Cenac (2000) indicated they found no cases of congenital malaria with clinical signs in their study. Furthermore four studies from various parts of Nigeria which examined both umbilical cord blood and neonatal blood for malaria parasites observed that the frequency and density of parasitaemia were consistently higher in cord blood than the neonatal blood (Lamikanra, 1993; Egwunyenga et al., 1995; Obiajunwa et al., 2005; Mukhtar et al., 2006). Therefore a proper estimation of congenital malaria must take these influencing factors into consideration to avoid underestimation of the prevalence of the disease. The stark reality however, is that congenital malaria is no longer a rare event.

\section{Mechanisms and clinical features of congenital malaria}

In spite of the increase in the number of recent reports indicating that congenital malaria frequently occurs, the mechanism of transplacental passage of the malaria parasite from mother to foetus is still obscure. It has been postulated that the possible mechanisms include direct penetration through chorionic villi, premature separation of the placenta, and the possible physiologic transfusion of maternal red blood cells to the foetal circulation in utero or at the time of delivery (De Silva et al., 1982; Menendez \& Mayor, 2007; Reynolds et al., 2007). A number of previous studies have identified many other factors that directly influence the occurrence of 
congenital malaria. These factors include: (i) pre-existing level of malaria immunity in the pregnant woman (Hviid, 2004; Bir et al., 2006; Rogerson et al., 2007); (ii) occurrence of severe malaria during pregnancy (Lagerberg, 2008; Coll et al., 2008); (iii) absence of immunity especially pregnant women travelling to endemic areas (Coll et al., 2008); (iv) placental malaria especially among primigravid and secundigravid women (Uneke, 2007c; 2008); and (v) maternal human immunodeficiency virus (HIV) infection (Uneke, 2007c; Perrault et al., 2009).

The onset of symptoms in congenital malaria typically occurs at 10-30 days postpartum (Behrman et al., 2004), which is the estimated half-life of maternal immunoglobulin $G$ in the infant (Reynolds et al., 2007). The most common clinical features in $80 \%$ of cases are fever, anaemia, and splenomegaly (Remington \& Klein, 1995) and these features can be observed in a day-old baby or in some cases be delayed for several weeks or even months (Hashemzadeh \& Heydarian, 2005). Other signs and symptoms include hepatomegaly, jaundice, regurgitation, loose stools, and poor feeding, and occasionally, drowsiness, restlessness, and cyanosis can also be seen (Hashemzadeh \& Heydarian 2005; Remington \& Klein 1995; Ibhanesebhor, 1995). The delay in the onset of the disease has been attributed to factors that may protect the infant initially, particularly infants born to mothers residing in endemic areas. These factors include foetal haemoglobin, abnormal haemoglobins that are resistant to malarial infection, the secretion of lymphocytes or macrophage-derived toxic substances across the placenta to foetal circulation, and partial malaria chemotherapy during pregnancy (Reynolds et al., 2007).

\section{Effect of maternal HIV infection on congenital malaria}

The human immunodeficiency virus (HIV) infection has been described as a major factor that is contributing to worsen the burden of malaria in most endemic areas particularly in sub-Saharan Africa (Abu-Raddad et al., 2006). Evidence abound indicating that HIV infection interacts negatively with malaria, with each disease driving the progression and transmission of the other (Whitworth et al., 2000; French et al., 2001; Patnaik et al., 2005). Some studies have demonstrated that HIV increases the risk of clinical and severe malaria, while malaria increases HIV replication in vitro and in vivo (Xiao et al., 1998; Whitworth et al., 2000; French et al., 2001; Patnaik et al., 2005; Kamya et al., 2006). Both HIV infection and malaria are known to critically intersect in pregnancy and have serious consequences in pregnant women, their foetuses and their infants (Ticconi et al., 2003; ter Kuile et al., 2004). It is estimated that approximately 1 million pregnancies per year are complicated by co-infection with malaria and HIV in subSaharan Africa (WHO, 2004). However, whether the dual infection with malaria and HIV in pregnancy increases the risk of congenital malaria is yet to be unequivocally established, as studies examining these relationships are few and have inconsistent findings and a wide range of unanswered questions (ter Kuile et al., 2004; Perrault et al., 2009; Uneke, 2009b).

Nevertheless, in a recent report from Western Kenya, Perrault et al. (2009) demonstrated that malaria and HIV co-infection in pregnancy increased placental parasite density and the rate of antenatal malaria transmission. The authors found that HIV serostatus was strongly correlated with cord blood infection, suggesting that HIV may impact congenital malaria primarily by allowing for higher parasite densities in the placenta (Perrault et al., 2009). This 
finding was consistent with an earlier report by Steketee et al. (1996b) who showed via a multivariate analysis that HIV infection was an important determinant of umbilical cord parasitaemia and added that HIV potentiates malaria infection in the umbilical blood of newborns especially in multigravidas. In addition, findings from another early study noted that HIV infection was associated with umbilical cord parasitaemia in univariate analysis and was probably acting as surrogate marker for maternal malaria infection (Reed et al., 1996). Reports from the $12^{\text {th }}$ World AIDS Conference in Geneva also provided additional information from various researchers indicating that the presence of HIV may reduce a pregnant woman's ability to control the perinatal transmission of malaria (Anderson, 1998).

On the contrary, reports from Kisumu, Kenya (van Eijk et al., 2002) and rural Malawi (Verhoeff et al., 1998), did not observe any consistent effect of maternal HIV on congenital malaria. Although it has been demonstrated that maternal HIV infection induces pathological changes in the placenta that potentially could interfere with the materno-fetal transfer of antibodies, the mechanism of this process and whether a decreased transfer of antibodies to some malaria antigens has an impact on increased susceptibility to congenital malaria is not known (WHO, 2005). Clearly more research is required to properly elucidate this interaction between malaria and HIV with respect to congenital malaria.

\section{Effects congenital malaria on infants}

There is a dearth of studies on the effects of congenital malaria on infants. The few available studies providing information on the burden of malaria in early infancy, especially the neonatal period reported a wide range of results that were inconclusive and contradictory (RunseweAbiodun et al., 2006; Ekanem et al., 2008; Mwaniki et al., 2010) . The direct burden of neonatal malaria infection in terms of prevalence and outcome is therefore not well described in malaria endemic areas. Available evidence however indicates that some newborns in endemic areas who are parasitaemic at birth, the parasites spontaneously clear without the newborn ever becoming ill (Lesko et al., 2007). The protective effect of the maternal antibodies passed to the newborn and also the protective role of the foetal haemoglobin in slowing the rate of parasite development are thought to be responsible for the parasite clearance (Sutherland et al., 2007; Moormann, 2009). In malaria endemic areas parasite clearance rates ranging from $87 \%$ to $100 \%$ have been documented (Obiajunwa et al., 2005; Mukhtar et al., 2006).

Congenital malaria in some newborns particularly those whose mothers are nonresidents of malarious areas, could be life threatening. The presence of malaria parasites in cord blood or in the asymptomatic newborn may be related to an increased risk of anaemia in infancy (Remington \& Klein, 1995; Ndyomugyenyi \& Magnussen, 2000; Hashemzadeh \& Heydarian, 2005). There is sufficient evidence indicating that malaria causes anaemia through haemolysis and increased splenic clearance of infected and uninfected red blood cells and cytokine-induced dyserythropoeisis (Menendez et al., 2000; Nagel, 2002; Ekvall, 2003). If untreated this could result in life-threatening anaemia, metabolic acidosis and, death (Ekvall et al., 2001; Crawley, 2004). In a comprehensive review on congenital malaria, Menendez \& Mayor (2007) noted that newborn exposure to blood-stage malaria antigens may have profound long- 
term effects during infancy and childhood by priming the immune responses of the foetus, by inducing immune tolerance, which could result in a reduced (priming) or increased (immune tolerance) susceptibility to malaria in the infant and child. This is however subject to further investigation and confirmation.

\section{Diagnosis of congenital malaria and the challenges}

The diagnosis of malaria in most developing countries particularly in sub-Saharan Africa has been described as very challenging (Uneke 2008b). Early and accurate diagnosis and appropriate case management are essential to addressing congenital malaria, and have been advocated consistently by the World Health Organization as one of the main interventions of the Global Malaria Control Strategy (WHO, 2000). Hence prompt and accurate diagnosis cannot be overstated because the congenital malaria caused by $P$. falciparum that is not diagnosed and promptly treated is potentially rapidly lethal, especially in babies born to non-immune women (Menendez \& Mayor, 2007).

A lot of diagnostic challenges are however, encountered when performing the diagnosis of malaria among the vulnerable groups like pregnant women and neonates in endemic areas such as sub-Saharan Africa (Uneke, 2008b). It is pertinent to state that most cases of congenital malaria are misdiagnosed initially because of the lack of specific symptoms and a general lack of awareness of this uncommon disease (Reynolds et al., 2008). Because malaria is endemic in this region, it is often difficult to diagnose, and thus report, "classic" congenital malaria (Uneke, $2007 \mathrm{~b}$ ). One of the major factors constituting diagnostic problems is that it is much more difficult to differentiate congenital malaria from those acquired from mosquitoes following delivery (Balatbat et al., 1995). Thus, the proponents of the rarity of congenital malaria have argued that the majority of the cases of malaria noticed in newborn infants in Africa were probably transmitted by mosquitoes (Uneke, 2007b). In fact, it was suggested that several diagnostic problems may also have been responsible for the increasing incidence of congenital malaria (Romand et al., 1994), in addition to the fact that the frequency of congenital malaria also depends on factors such as perinatal clearance of occult parasitemia, maternal immunity, and coexisting infections (Miller \& Telford, 1997).

The diagnosis of malaria is established by the microscopic identification of organisms on Giemsa-stained smears of peripheral thick or thin blood smears. The Giemsa-stained smears diagnostic technique is widely used in most malarious areas for the diagnosis of congenital malaria. This technique is considered fraught by many pitfalls including: artifacts often mistaken for parasites; Maurer's clefts often confused with Schuffner's dots, causing $P$. falciparum to be diagnosed as Plasmodium vivax; Babesia and Bartonella infections often mistaken for malaria; young gametocytes of P. falciparum often mistaken for P. vivax (WHO, 2000). In addition to this, there is a high chance of not finding the parasite by the microscopic method in babies that are having congenital malaria. Stauffer \& Fischer (2003), had reported that a single smear without parasites is not sufficient to rule out malaria.

In Gaziantep, Turkey for instance, researchers studying congenital malaria were able to find malaria parasites only in repeat blood smears (Bappýnar et al., 2006), and in India, 
congenital malaria was detected accidentally in cases investigated because they were essentially asymptomatic (Kothare et al., 1987). Findings from a recent study in Western Kenya indicated that the prevalence of placental and cord blood infections were $17.2 \%$ and $0 \%$ by microscopy, and $33.1 \%$ and $10.8 \%$ by polymerase chain reaction (Perrault et al., 2009). These findings suggest that the diagnosis of malaria in neonates using the microscopic technique is frequently missed and previous estimates of congenital malaria prevalence may be under-representative because of the limited sensitivity of light microscopy used in the majority of studies (Perrault et al., 2009). There is evidence proving that congenital malaria is usually mistaken for sepsis or infections in the TORCHS syndrome (toxoplasmosis, rubella, cytomegalovirus, herpes, and syphilis) (Hulbert, 1992). Therefore for the purpose of performing accurate diagnosis of congenital malaria, a good index of suspicion, a careful physical examination and repeated peripheral blood smears are therefore needed (Perrault et al., 2009). Sometimes, parasitemia cannot be shown on blood smear, and plasmodial antigen detection or polymerase chain reaction of the blood may be necessary (Perrault et al., 2009).

\section{Treatment of congenital malaria}

There are very few recent studies that have provided information and data on appropriate and effective treatment of congenital malaria. However, there are no clearly established protocols for the clinical management of congenital or neonatal malaria. Menendez \& Mayor (2007) noted in their review that in order to establish treatment recommendations it would be useful to distinguish between babies born to non-immune women, in which case congenital falciparum malaria, whether symptomatic or not, should be treated with quinine $(10 \mathrm{mg} / \mathrm{kg}$ orally every 8 $\mathrm{h}$, or same dosage in intravenous infusion until oral administration is possible). However there have been reports of high level of chloroquine resistance in the treatment of malaria by a number of studies. In Pakistan, chloroquine resistance of $26.66 \%$ was recorded among babies born with congenital malaria and this resulted in a mortality rate of $16.66 \%$ (Khichi et al., 2005).

In Nigeria a cure rate of $89.1 \%$ was recorded in the treatment of babies with symptomatic congenital malaria with oral chloroquine but the treatment failures subsequently received oral sulfadoxine-pyrimethamine with good outcome (Orogade et al., 2008). In another recent study by Harrington \& Duffy (2008), quinine plus clindamycin was reported as being effective in the treatment of $P$. falciparum congenital malaria, and chloroquine for the treatment of other malaria parasites, such as $P$. vivax. The authors added that severe cases of congenital malaria should be managed with intravenous quinine or with intravenous artesunate, which has recently been approved for investigational use in some countries including the United States. The same authors have advised that primaquine is not required for infants with congenital P. vivax or P. ovale, but should be offered to their mothers after excluding G6PD deficiency (Harrington \& Duffy, 2008). In a very recent study in India, it was reported that a baby with congenital malaria failed to respond to chloroquine treatment but responded well when oral artesunate was used (Avabratha et al., 2010).

The rising incidence of resistance to chloroquine which has been the drug of choice in malaria treatment necessitates investigation on the efficacy of other antimalarials for the 
treatment of congenital malaria. There are very few studies reporting the use of drugs such as quinine, artesunate and mefloquine in neonates and the studies with use of oral artesunate is even scanty (Patel \& Belsare, 2002; Ming, 2008). These drugs have been used effectively in older children and could be hence adapted for neonates to treat congenital malaria. In China, a study comparing the efficacy of artesunate versus quinine in the treatment of congenital malaria observed that the total effective rates of the artesunate treatment group and the quinine group were $92.31 \%$ and $83.33 \%$ and the clearance rates of plasmodium were $92.31 \%$ and $78.57 \%$, respectively (Patel \& Belsare, 2002). The study therefore demonstrated that efficacy of artesunate over quinine and noted that it can be used as drug of first choice for treatment of congenital malaria. More studies are however required to further elucidate the potency of artesunate in the treatment of congenital malaria.

\section{Conclusion}

A very vital lesson derived from this review of the reports on congenital malaria is that the disease is no longer an uncommon occurrence. Congenital malaria has now assumed a public health concern both in malaria endemic and semi-endemic areas. As countries all over the world and international aid agencies such as WHO intensify efforts towards the control of malaria it is important that such efforts do not neglect congenital malaria control. There is clearly a lack well established guidelines for the definition, diagnosis and treatment of congenital malaria. Operational research into various aspects of congenital malaria is also essentially lacking as many unresolved issues requiring urgent scientific investigation abound. Public health policy on malaria control should also take into cognizance the importance of integrating guidelines on congenital malaria management and control.

\section{References}

Abu-Raddad, L.J., Patnaik, P. \& Kublin, J.G. (2006) Dual infection with HIV and malaria fuels the spread of both diseases in sub-Saharan Africa. Science 314, 1603-1606.

Achidi, E.A. \& Salimonu, L.S. (1997) Malaria parasitaemia and immunoglobulin levels in paired maternal-cord sera from south western Nigeria. African Journal of Medicine and Medical Sciences 26, 167-170.

Adachi, M., Manji, K., Ichimi, R., Nishimori, H., Shindo, K., Matsubayashi, N., Mbise, R.L., Massawe, A., Liu, Q., Kawamoto, F., Chinzei, Y., Sakurai, M. (2000) Detection of congenital malaria by polymerase-chain-reaction methodology in Dar es Salaam, Tanzania. Parasitology Research 86, 615-618.

Afolabi, B.M., Salako, L.A., Mafe, A.G., Ovwigho, U.B., Rabiu, K.A., Sanyaolu, N.O. \& Ibrahim, M.M. (2001) Malaria in the first 6 months of life in urban African infants with anemia. American Journal of Tropical Medicine and Hygiene 65, 822-827.

Akindele, J.A., Sowunmi, A. \& Abohweyere, A.E. (1993) Congenital malaria in a hyperendemic area: a preliminary study. Annals of Tropical Paediatrics 13, 273-276. 
Akum, A.E., Kuoh, A.J., Minang, J.T., Achimbom, B.M., Ahmadou, M.J. \& Troye-Blomberg, M. (2005) The effect of maternal, umbilical cord and placental malaria parasitaemia on the birthweight of newborns from South-western Cameroon. Acta Paediatrica 94, 917-923.

Anderson, J.R. (1998) Report from Geneva: women and HIV. Hopkins HIV Report 10, 12-13.

Avabratha, K.S., Chettiyar, L.A. \& John, N.P. (2010) Oral artesunate for neonatal malaria. Journal of Tropical Pediatrics 56, 452-453.

Balatbat, A.B.N., Jordan, G.W. \& Halsted, C. (1995) Congenital malaria in a nonidentical twin. Western Journal of Medicine 162, 458-459.

Bappýnar, O., Bayraktarðlu, Z., Karslýgil, T. \& Bayram, A. (2006) A rare cause of anemia and thrombocytopenia in a newborn: malaria. Turkish Journal of Pediatrics 48, 63-65.

Behrman, R.E., Keligman, R. \& Jenson, H.B. (2004) Nelson Textbook of Pediatrics, 17th edn. WB Saunders, Philadelphia. 2004.

Bergstrom, S., Fernandes, A., Schwalbach, J., Perez, O. \& Miyar, R. (1993) Materno-fetal transmission of pregnancy malaria: an immunoparasitological study on 202 parturients in Maputo. Gynecologic and Obstetric Investigation 35, 103-107.

Bhutta, Z.A., Darmstadt, G.L., Hasan, B.S. \& Haws, R.A. (2005) Community-based interventions for improving perinatal and neonatal health outcomes in developing countries: a review of the evidence. Pediatrics 115, 519-617.

Bir, N., Yazdani, S.S., Avril, M., Layez, C., Gysin, J. \& Chitnis, C.E. (2006) Immunogenicity of Duffy binding-like domains that bind chondroitin sulfate $\mathrm{A}$ and protection against pregnancy-associated malaria. Infection Immunology 74, 5955-5963.

Brabin, B.J. (1983) An analysis of malaria in pregnancy in Africa. Bulletin of World Health Organization 61, 1005-1016.

Brabin, B.J., Romagosa, C., Abdelgalil, S., Menéndez, C., Verhoeff, F.H., McGready, R., Fletcher, K.A., Owens, S., D'Alessandro, U., Nosten, F., Fischer, P.R. \& Ordi, J. (2004) The sick placenta-the role of malaria. Placenta 25, 359-378.

Bruce-Chwatt, L.J.(1952) Malaria in African infants and children in southern Nigeria. Annals of Tropical Medicine and Parasitology 46, 173-200.

Coll, O., Menendez, C., Botet, F., Dayal, R., World Association of Perinatal Medicine Perinatal Infections Working Group., Carbonell-Estrany, X., Weisman, L.E., Anceschi, M.M., Greenough, A., Gibss, R.S. \& Ville Y. (2008) Treatment and prevention of malaria in pregnancy and newborn. Journal of Perinatal Medicine 36, 15-29.

Covell, G. (1950) Congenital malaria. Tropical Disease Bulletin 47, 1147-1165.

Crawley, J. (2004) Reducing the burden of anemia in infants and young children in malariaendemic countries of Africa: from evidence to action. American Journal of Tropical Medicine and Hygiene 71, 25-34.

Davis, T.M., Mueller, I. \& Rogerson, S.J. (2010) Prevention and treatment of malaria in pregnancy. Future Microbiology 5, 1599-1613.

De Silva, D.H.G., Mendis, K.N., Premaratne, U.N., Jayatilleke, S.M.D. \& Soyza, P.E. (1982) Congenital malaria due to Plasmodium vivax: A case report from Sri Lanka. Transactions of the Royal Society of Tropical Medicine and Hygiene 75, 33-35. 
DFID (2004). Department for International Development DFID. Fact Sheet-Malaria. 2004. Available at: http://www.dfid.gov.uk/pubs/files/malaria-factsheet.pdf Accessed January 10, 2011.

Djibo, A. \& Cenac, A. (2000) Congenital malaria. Parasitological and serological studies in Niamey (Niger). Sante 10, 183-187.

Duah, N.O., Miles, D.J., Whittle, H.C. \& Conway, D.J. (2010) Acquisition of antibody isotypes against Plasmodium falciparum blood stage antigens in a birth cohort. Parasite Immunology $32,125-134$.

Egwunyenga, O.A., Ajayi, J.A. \& Duhlinska-Popova, D.D. (1995) Transplacental passage of Plasmodium falciparum and seroevaluation of newborns in northern Nigeria. Journal of Communicable Diseases 27, 77-83.

Egwunyenga, O.A., Ajayi, J.A., Popova-Duhlinska, D.D. \& Nmorsi, O.P. (1996) Malaria infection of the cord and birthweights in Nigerians. Central African Journal of Medicine 42, 265-268.

Ekanem, A.D., Anah, M.U. \& Udo, J.J. (2008) The prevalence of congenital malaria among neonates with suspected sepsis in Calabar, Nigeria. Tropical Doctor 38, 73-76.

Ekvall, H. (2003) Malaria and anemia. Current Opinion in Hematology 10, 108-114.

Ekvall, H., Arese, P., Turrini, F., Ayi, K., Mannu, F., Premji, Z. \& Bjorkman A. (2001). Acute haemolysis in childhood falciparum malaria. Transactions of the Royal Society of Tropical Medicine and Hygiene 95, 611-617.

Falade, C., Mokuolu, O., Okafor, H., Orogade, A., Falade, A., Adedoyin, O., Oguonu, T., Aisha, M., Hamer, D.H., Callahan, M.V. (2007) Epidemiology of congenital malaria in Nigeria: a multi-centre study. Tropical Medicine and International Health 12, 1279-1287.

Fischer, P.R. (1997) Congenital malaria: an African survey. Clinical Pediatrics 36, 411-413.

French, N., Nakiyingi, J., Lugada, E., Watera, C., Whitworth, J.A. \& Gilks, C.F. (2001) Increasing rates of malarial fever with deteriorating immune status in HIV-1-infected Ugandan adults. AIDS 15, 899-906.

Guerra, C.A., Howes, R.E., Patil, A.P., Gething, P.W., Van Boeckel, T.P., Temperley, W.H., Kabaria, C.W., Tatem, A.J., Manh, B.H., Elyazar, I.R., Baird, J.K., Snow, R.W. \& Hay, S.I. (2010) The international limits and population at risk of Plasmodium vivax transmission in 2009. PLoS Neglected Tropical Diseases 4, e774.

Gyapong, M. \& Garshong, B. (2007) Lessons learned in Home Management of Malaria: Implementation research in four African countries. Geneva, World Health Organization.

Hanlin, R.B. (2002) Congenital infections and preconception counseling. Journal of South Carolina Medical Association 98, 277-280.

Harrington, W.E. \& Duffy, P.E. (2008) Congenital malaria: rare but potentially fatal. Pediatric Health 2, 235-248.

Hashemzadeh, A. \& Heydarian, F. (2005) Congenital malaria in a neonate. Archives of Iranian Medicine 8, 226-228.

Hopkins, H., Talisuna, A., Whitty, C.J.M. \& Staedke, S.G. (2007) Impact of homebased management of malaria on health outcomes in Africa: a systematic review of the evidence. Malaria Journal 6, 134. 
Hulbert, T.V. (1992) Congenital malaria in the United States: report of a case and review. Clinical Infectious Diseases 14, 922-926.

Hviid, L. (2004) The immuno-epidemiology of pregnancy-associated Plasmodium falciparum malaria: a variant surface antigen-specific perspective. Parasite Immunology 26, 477-486.

Ibhanesebhor, S.E. (1995) Clinical characteristics of neonatal malaria. Journal of Tropical Pediatrics 41, 330-333.

Kamya, M.R., Gasasira, A.F., Yeka, A., Bakyaita, N., Nsobya, S.L., Francis, D., Rosenthal, P.J., Dorsey, G., Havlir, D. (2006) Effect of HIV-1 infection on antimalarial treatment outcomes in Uganda: a population-based study. Journal of Infectious Diseases 193, 9-15.

Khichi, Q.H., Channar, M.S., Wairraich, M.I. \& Butt, A. (2005) Chloroquine resistant malaria in neonates. Journal of the College of Physicians and Surgeons Pakistan 151, 34-36.

Klein Klouwenberg, P.M., Oyakhirome, S., Schwarz, N.G., Glaser, B., Issifou, S., Kiessling, G., Klopfer, A., Kremsner, P.G., Langin, M., Lassmann, B., Necek, M., Pötschke, M., Ritz, A., Grobusch, M.P. (2005) Malaria and asymptomatic parasitaemia in Gabonese infants under the age of 3 months. Acta Tropica 95, 81-85.

Kothare, S.V., Kallapur, S.G., Irani, S.F., Prabhu, S.B., Gangal, P.S. \& Agarwal, G.J. (1987) Congenital malaria (a report of 2 cases). Journal of Postgraduate Medicine 33, 158-161.

Lagerberg, R.E. (2008) Malaria in pregnancy: a literature review. Journal of Midwifery and Women's Health 53, 209-215.

Lamikanra, O.T. (1993) A study of malaria parasitaemia in pregnant women, placentae, cord blood and newborn babies in Lagos, Nigeria. West African Journal of Medicine 12, 213-217.

Larkin, G.L. \& Thuma, P.E. (1991) Congenital malaria in a hyperendemic area. American Journal of Tropical Medicine and Hygiene 45, 587-592.

Larru, B., Molyneux, E, Ter Kuile F.O., Taylor, T., Molyneux, M. \& Terlouw, D.J. (2009) Malaria in infants below six months of age: retrospective surveillance of hospital admission records in Blantyre, Malawi. Malaria Journal 8, 310.

Lehner, P.J. \& Andrews, C.J.A. (1988) Congenital malaria in Papua New Guinea. Transactions of the Royal Society of Tropical Medicine and Hygiene 2, 822-826.

Lesi, F.E., Mukhtar, M.Y., Iroha, E.U. \& Egri-Okwaji, M.T. (2010) Clinical presentation of congenital malaria at the Lagos University Teaching Hospital. Nigeria Journal of Clinical Practice 13, 134-138.

Lesko, C.R., Arguin, P.M. \& Newman, R.D. (2007) Congenital malaria in the United States: a review of cases from 1966 to 2005. Archives of Pediatrics and Adolescent Medicine 161, 10621067.

Logic, D.E. \& McGregor, I.A. (1970) Acute malaria in newborn infants. British Medical Journal ii, 404-405.

Malhotra, I., Mungai, P., Muchiri, E., Kwiek, J.J., Meshnick, S.R. \& King, C.L. (2006) Umbilical cord-blood infections with Plasmodium falciparum malaria are acquired antenatally in Kenya. Journal of Infectious Diseases 194, 176-183.

McGovern, L.M., Boyce, T.G. \& Fischer, P.R. (2007) Congenital infections associated with international travel during pregnancy. Journal of Travel Medicine 14, 117-128. 
McGregor, I.A., Wilson, M.E. \& St Billewicz, W.Z. (1983) Malaria infection of the placenta in the Gambia, West Africa; its incidence and relationship to stillbirth, birthweight and placental weight. Transactions of the Royal Society of Tropical Medicine and Hygiene 77, 232244.

Menendez, C. \& Mayor, A. (2007) Congenital malaria: the least known consequence of malaria in pregnancy. Seminars in Fetal and Neonatal Medicine 12, 207-213.

Menendez, C., Fleming, A.F. \& Alonso, P.L. (2000) Malaria-related anaemia. Parasitology Today $16,469-476$.

Miller, I.J. \& Telford, S.R. III. (1997) Congenital malaria. New England Journal of Medicine 336, 7172.

Ming, H.K. (2008) Treatment of 39 congenital malaria with artesunate. China Tropical Medicine 8, 223-224.

Moormann, A.M. (2009) How might infant and paediatric immune responses influence malaria vaccine efficacy? Malaria Journal 31, 547-559.

Mukhtar, M.Y., Lesi, F.E., Iroha, E.U., Egri-Okwaji, M.T. \& Mafe, A.G. (2006) Congenital malaria among inborn babies at a tertiary centre in Lagos, Nigeria. Journal of Tropical Pediatrics $52,19-23$.

Murphy, S.C. \& Breman, J.G. (2001) Gaps in the childhood malaria burden in Africa: cerebral malaria, neurological sequelae, anemia, respiratory distress, hypoglycemia, and complications of pregnancy. American Journal of Tropical Medicine Hygiene 64, 57-67.

Mwangoka, G.W., Kimera, S.I. \& Mboera, L.E.G. (2008). Congenital Plasmodium falciparum infection in neonates in Muheza District, Tanzania. Malaria Journal 7, 117.

Mwaniki, M.K., Talbert, A.W., Mturi, F.N., Berkley, J.A., Kager, P., Marsh, K. \& Newton, C.R. (2010) Congenital and neonatal malaria in a rural Kenyan district hospital: an eight-year analysis. Malaria Journal 9, 313.

Nagel, R.L. (2002) Malarial anemia. Hemoglobin 26, 329-343.

Ndyomugyenyi, R. \& Magnussen, P. (2000) Chloroquine prophylaxis, iron/folic-acid supplementation or case management of malaria attacks in primigravidae in western Uganda: effects on congenital malaria and infant haemoglobin concentrations. Annals of Tropical Medicine and Parasitology 94, 759-770.

Nimir, A.R., Isa, N.H., Eugene, C.B., Ghauth, I.M., Salleh, F.M., \& Rahman, R.A. (2006) Severity of Malaria cases reported in urban and rural hospitals in Malaysia. Southeast Asian Journal of Tropical Medicine and Public Health 37, 831-837.

Nweneka, C.V. \& Eneh, A.U. (2004) Malaria parasitaemia in neonates in Port Harcourt, Nigeria. Journal of Tropical Pediatrics 50, 114-116.

Obiajunwa, P.O., Owa, J.A. \& Adeodu, O.O. (2005) Prevalence of congenital malaria in Ile-Ife, Nigeria. Journal of Tropical Pediatrics 51, 219-222.

Okafor, U.H., Oguonu, T. \& Onah, H.E. (2006) Risk factors associated with congenital malaria in Enugu, South Eastern Nigeria. Journal of Obstetrics and Gynaecology 26, 612-616.

Olowu, J.A., Sowunmi, A. \& Abohweyere, A.E. (2000) Congenital malaria in a hyperendemic area: a revisit. African Journal of Medicine and Medical Sciences 29, 211-213. 
Omanga, U. \& Kapepela, K. (1990) Epidemiology of congenital malaria in the urban milieu of Kinshasa (Zaire). Annales de Pediatrie 37, 195-197.

Orogade, A.A., Falade, C.O., Okafor, H.U., Mokuolu, O.A. \& Mamman, A.I. (2008) Clinical and laboratory features of congenital malaria in Nigeria. Journal of Pediatric Infectious Diseases 3, 181-187.

Patel, A.B. \& Belsare, H.S. (2002) Resistant malaria in a neonate. Indian Pediatrics 39, 585- 588.

Patnaik, P., Jere, C.S., Miller, W.C., Hoffman, I.F., Wirima, J., Pendame, R., Meshnick, S.R., Taylor, T.E., Molyneux, M.E., Kublin, J.G. (2005) Effects of HIV-1 serostatus, HIV-1 RNA concentration, and CD4 cell count on the incidence of malaria infection in a cohort of adults in rural Malawi. Journal of Infectious Diseases 192, 984-991.

Perrault, S.D., Hajek, J., Zhong, K., Owino, S.O., Sichangi, M., Smith, G., Shi, Y.P., Moore, J.M., Kain, K.C. (2009) Human immunodeficiency virus co-infection increases placental parasite density and transplacental malaria transmission in Western Kenya. American Journal of Tropical Medicine and Hygiene 80, 119-125.

Redd, S.C., Wirima, J.J., Steketee, R.W., Breman, J.G. \& Heynann, D.L. (1996) Transplacental transmission of Plasmodium falciparum in rural Malawi. American Journal of Tropical Medicine and Hygiene 55, 57-60.

Reinhrdt, M.C., Ambroise-Thomas, P., Cavallo-Serra, R., Meylan, C. \& Gautier R. (1978) Malaria at delivery in Abidjan. Helvetica Paediatrica Acta 33, 65-84.

Remington, J.S. \& Klein, J.O. (1995) Infectious Diseases of the Fetus and Newborn Infant. 3rd edn. WB Saunders, Philadelphia.

Reynolds, S., Bollinger, R. \& Quinn, T.C. (2008) Parasitic Diseases During Pregnancy. Global Library of women's medicine (ISSN: 1756-2228); DOI 10.3843/GLOWM.10188. Available at: http://www.glowm.com/? Accessed January 10, 2011.

Rogerson, S.J, Mwapasa, V. \& Meshnick, S.R. (2007) Malaria in pregnancy: linking immunity and pathogenesis to prevention. American Journal of Tropical Medicine and Hygiene 77, 1422.

Romand, S., Bouree, P., Gelez, J., Bader-Meunier, B., Bisaro, F. \& Dommergues, J.P. (1994) Congenital malaria. A case observed in twins born to an asymptomatic mother. Presse Medicale 23, 797-800.

Rowe, A.K., Rowe, S.Y., Snow, R.W., Korenromp, E.L., Armstrong Schellenberg, J.R.M., Stein, C., Nahlen, B., Bryce, J., Black, R.E. \& Steketee, R.W. (2006) The burden of malaria mortality among African children in the year 2000. International Journal of Epidemiology $35,691-704$.

Runsewe-Abiodun, I.T., Ogunfowora, O.B. \& Fetuga, B.M. (2006) Neonatal malaria in Nigeria-a 2 year review. BMC Pediatrics 6, 19.

Schantz-Dunn, J. \& Nour, N.M. (2009) Malaria and pregnancy: a global health perspective. Reviews in Obstetrics and Gynecology 2, 186-192.

Schwetz, J. \& Peel, M. (1934) Congenital malaria and placental infections amongst the negroes of Central Africa. Transactions of the Royal Society of Tropical Medicine and Hygiene 28, 167174. 
Sharp, B., Kleinschmidt, I., Streat, E., Maharaj, R., Barnes, K., Durrheim, D.N., Ridl, F.C., Morris, N., Seocharan, I., Kunene, S., La Grange, J.J.P., Mthembu, J.D., Maartens, F., Martin, C.L. \& Barreto, A. (2007) Seven years of regional malaria control collaboration-Mozambique, South Africa and Swaziland. American Journal of Tropical Medicine and Hygiene 76, 42-47.

Snow, R.W., Korenromp, E.L. \& Gouws, E. (2004) Pediatric mortality in Africa: Plasmodium falciparum malaria as a cause or risk? American Journal of Tropical Medicine $\mathcal{E}$ Hygiene 71, 16-24.

Snow, R.W., Nahlen, B., Palmer, A., Donnelly, C.A., Gupta, S. \& Marsh, K. (1998) Risk of severe malaria among African infants: direct evidence of clinical protection during early infancy. Journal of Infectious Diseases 177, 819-822.

Sotimehin, S.A., Runsewe-Abiodun, T.I., Oladapo, O.T., Njokanma, O.F. \& Olanrewaju, D.M. (2008) Possible risk factors for congenital malaria at a tertiary care hospital in Sagamu, Ogun State, South-West Nigeria. Journal of Tropical Pediatrics 54, 313-320.

Stauffer, W. \& Fischer, P.R. (2003) Diagnosis and treatment of malaria in children. Clinical Infectious Diseases 37, 1340-1348.

Steketee, R.W., Nahlen, B.L., Parise, M.E. \& Menendez, C. (2001) The burden of malaria in pregnancy in malaria-endemic areas. American Journal of Tropical Medicine Hygiene 64, 2835.

Steketee, R.W., Wirima, J.J., Slutsker, L., Heymann, D.L. \& Breman, J.G. (1996a) The problem of malaria and malaria control in pregnancy in sub-Saharan Africa. American Journal of Tropical Medicine and Hygiene 5, 2-7.

Steketee, R.W., Wirima, J.J., Slutsker, L., Roberts, J.M., Khoromana, C.O., Heymann, D.L. \& Breman, J.G. (1996b) Malaria parasite infection during pregnancy and at delivery in mother, placenta, and newborn: efficacy of chloroquine and mefloquine in rural Malawi. American Journal of Tropical Medicine and Hygiene 55, 24-32.

Sule-Odu, A.O., Ogunledun, A. \& Olatunji, A.O. (2002) Impact of asymptomatic maternal malaria parasitaemia at parturition on perinatal outcome. Journal of Obstetrics and Gynaecology 22, 25-28.

Sutherland, C.J., Drakeley, C.J. \& Schellenberg, D. (2007) How is childhood development of immunity to Plasmodium falciparum enhanced by certain antimalarial interventions? Malaria Journal 6, 161.

Tagbor, H., Bruce, J., Browne, E., Greenwood, B. \& Chandramohan, D. (2008) Malaria in pregnancy in an area of stable and intense transmission: is it asymptomatic? Tropical Medicine and International Health 13, 1016-1021.

ter Kuile, F.O., Parise, M.E., Verhoeff ,F.H., Udhayakumar, V, Newman, R.D., van Eijk, A.M., Rogerson $_{\iota}$ S.J. \& Steketee ${ }_{\iota}$ R.W. (2004) The burden of co-infection with human immunodeficiency virus type 1 and malaria in pregnant women in sub-Saharan Africa. American Journal of Tropical Medicine and Hygiene 71, 41-54.

Ticconi, C., Mapfumo, M., Dorrucci, M., Naha, N., Tarira, E., Pietropolli, A., Rezza, G. (2003) Effect of maternal HIV and malaria infection on pregnancy and perinatal outcome in Zimbnabwe. Journal of Acquired Immune Deficiency Syndrome 34, 289-294. 
Uneke, C.J. (2007a) Impact of placental Plasmodium falciparum malaria on pregnancy and perinatal outcome in sub-Saharan Africa: I: Introduction to Placental Malaria. Yale Journal of Medicine and Biology 80, 39-50.

Uneke, C.J. (2007b) Congenital Plasmodium falciparum malaria in sub-Saharan Africa: a rarity or frequent occurrence? Parasitology Research 101, 835-842.

Uneke, C.J. (2007c) Impact of placental Plasmodium falciparum malaria on pregnancy and perinatal outcome in sub-Saharan Africa. II: Effects of Placental Malaria on Perinatal Outcome; Malaria and HIV. Yale Journal of Medicine and Biology 80, 95-103.

Uneke, C.J. (2008a) Impact of placental Plasmodium falciparum malaria on pregnancy and perinatal outcome in sub-Saharan Africa. III: Placental malaria, maternal health and public health. Yale Journal of Medicine and Biology 8, 1-7.

Uneke, C.J. (2008b) Diagnosis of Plasmodium falciparum malaria in pregnancy in sub-Saharan Africa: the challenges and public health implications. Parasitology Research 101, 835-842.

Uneke, C.J. (2009a) Impact of home management of Plasmodium falciparum malaria on childhood malaria control in sub-Saharan Africa. Tropical Biomedicine 26, 182-199.

Uneke, C.J. (2009b) Impact of placental malaria and HIV co-infection on congenital malaria and perinatal HIV transmission in sub-Saharan Africa: an overview. Parassitologia 51, 35-41.

van Eijk, A.M., Ayisi, J.G., ter Kuile, F.O., Misore, A.O., Otieno, J.A., Kolczak, M.S., Kager, P.A., Steketee, R.W. \& Nahlen, B.L. (2002) Placental malaria and HIV infection as risk factors for post-neonatal infant mortality in Kisumu, Kenya. The XIV International AIDS Conference. Barcelona, Spain.

van Geertruyden, J.P., Thomas, F., Erhart, A. \& D'Alessandro, U. (2004) The contribution of malaria in pregnancy to perinatal mortality. American Journal of Tropical Medicine and Hygiene 71, 35-40.

Verhoeff, F.H., Brabin, B.J., Chimsuku, L., Kazembe, P., Russell, W.B. \& Broadhead, R.L. (1998) An evaluation of the effects of intermittent sulfadoxine-pyrimethamine treatment in pregnancy on parasite clearance and risk of low birthweight in rural Malawi. Annals of Tropical Medicine and Parasitology 92, 141-150.

Whitworth, J., Morgan, D., Quigley, M., Smith, A., Mayanja, B., Eotu, H., Omoding, N., Okongo, M., Malamba, S., Ojwiya, A. (2000) Effect of HIV-1 and increasing immunosuppression on malaria parasitaemia and clinical episodes in adults in rural Uganda: a cohort study. Lancet 356, 1051-1056.

WHO (1992) World malaria situation, 1990. WHO Weekly Epidemiological Record 67, 161-167.

WHO (1997) World malaria situation in 1994. Weekly Epidemiological Record 72, 285-290.

WHO (2000) Expert Committee on Malaria. WHO technical report series 892, i-v. Geneva World Health Organization.

WHO (2000) Severe falciparum malaria. Transactions of the Royal Society of Tropical Medicine and Hygiene 94, S1-S90.

WHO (2003) The African Malaria Report 2003. WHO, 17-23. Geneva, World Health Organization.

WHO (2004) Malaria and HIV/AIDS interactions and implications: conclusions of a technical consultation convened by WHO, 23-25 June 2004. Geneva: World Health Organization. 
Available at: http://www.who.int/malaria/malaria HIV/malaria hiv flyer.pdf Accessed January 10, 2011

WHO (2005) Malaria and HIV Interactions and their Implications for Public Health Policy. Report of a Technical Consultation on Malaria and HIV Interactions and Public Health Policy Implications 2004. World Health Organization, 20 Avenue Appia, Geneva, Switzerland.

WHO (2008) World Malaria Report 2008. Geneva, Switzerland. World Health Organization.

WHO (2009) World Malaria Report 2009. Geneva, Switzerland. World Health Organization.

Worral, E., Basu, S. \& Hanson, K. (2005) Is malaria a disease of poverty? A review of literature. Tropical Medicine and International Health 10, 1047-1059.

Xiao, L.H., Owen, S.M., Rudolph, D.L., Lal, R.B. \& Lal, A.A. (1998) Plasmodium falciparum antigen-induced human immunodeficiency virus type 1 replication is mediated through induction of tumor necrosis factor-alpha. Journal of Infectious Diseases 177, 437-445. 